\title{
The Effective Role of Hospital Information System in Medicine and Healthcare
}

\author{
N. Rajendhiran, S. B. Hidayath Ahamed
}

\begin{abstract}
In the present day world of development it has become inevitable to supplement the growing population with adequate and proper health facilities and services. Though the hospitals are growing in size quality of service always remains a question mark for them due to the ever incrementing need for medical facilities. Integrating any service with technology always remains as the answer to these varying problems by these public utility services. Hospital information systems are one such variant of integrated technology that aids the hospitals in their everyday issues confronted with them. The multiple varieties of health-care facilities has demanded the creation of Health information technologies (HIT) to give solution for the troubles before they have identified; the increasing expenses and demand for the health- care facilities expecting a lot from the society. Via leveraging HIT with an integration of health center functions and approaches, health Hospital information services (HIS) are frequently followed among most fitness-care centers to fulfill administrative requisites. To fulfill the strategic aim of HIT, it targeted to improve the personal care facilities and cost reduction as a primary factor. The main aim of this paper is understand the basic concept of HIS and its implication on the hospital management. The study attempts to meet its objectives by preparing a questionnaire with regard to the hospital management and receive their opinion on the same for further analysis. Hospital information system (HIS) has the capacity in lowering healthcare expenditure and in enhancing fitness outcomes. The purpose of this paper is to explore the role of HIS in healthcare in and its different regulatory and organizational settings. This paper targeted to examine the impact of clinic statistics structures in improving health care in hospital. Primary data figures became accumulated through distributing questionnaire to patients, doctors and the staff treating them.
\end{abstract}

At the end of the study it was felt that the integration of technology with any public utility service would benefit the public at large and also give prompt output when needed. Since the technology is a comparatively new one it needs a bit of awareness among the general public to access it also knowledge is required on part of the doctors also to use it in a better and easy manner.

One of the most significant elements in health center is to access the computer systems which emphasis the availability of computer and computer systems to facilitate direct and instantaneous information access at the point of care. The process of HIS has increased the time spent in hospital which results in the development of overall performance and responsiveness phases.

\section{INTRODUCTION}

Hospitals are the most challenging organizations as the two most extreme phases of life, birth and death marking the

Revised Version Manuscript Received on 16 September, 2019.

Dr.N.Rajendhiran, Professor-Cum-Director (Rtd), Periyar Institute of Management Studies (PRIMS), Periyar University, Salem-636011.Tamil Nadu, India, drrajanprims@gmail.com

S.B.Hidayath Ahamed, Ph.D Scholar (Part Time), Department of Management Studies Periyar University Salem-636011.Tamil Nadu,India hidhawk13@gmail.com beginning and end of human life take place at the same locations with different circumstances. Doctors happen to be conceived and perceived as the god for most of them. With the present increase in population accompanied by illness and diseases around the world, it has become inevitable for hospitals to accordingly expand and accommodate the increasing number in these various nations. Technological inventions and innovations have been taken up as the major developments since the industrial revolution. Hospitals being such complex institutions with various departments and issues to handle, it has become the need of the hour to align technology and its variants in the field of health and healthcare as well. One such variant that we would be interested in knowing and discussing is Hospital information system (HIS).

The Hospital information system is in excessive demand to handle the expanded waft of patients and growing population and also aids the doctors and assists staffs. Hospital information system manages operational sports and enhances management and manipulates patient care, cost reduction and accelerates revenue. In widespread, you could define HIS as comprehensive software for affected person records integration, and to change comprehensive affected person statistics among wards and different medical centers which will expedite the manner of patient care, improve first-class, growth patient satisfaction and decrease cost. An extremely good purpose of countrywide healthcare machine is not viable without the usage of clinic statistics structures. Health center information structures control guy features in hospitals together with admissions/discharge/transfers, pathology check end result records, radiology check with appointment scheduling, special check information systems in clinical research, inventory upkeep of drug treatments and other appliances, troubles of drugs for sufferers, communications with the external world and patient billing. Hospital information system (HIS) can be defined as a cohesive information network which enhances patient care by improving the user's information base and minimizing risk permitting prompt decisions to be crafted from the information furnished.

In the present scenario, to manage the economic, clinical and administrative factors of healthcare centers and hospitals they are introducing the technology called HIS which is perfect and multi component statistics system. HIS is considered as the one of the best criteria for hospitals which enriches the healthcare facilities and medical developments. The main importance and purpose of the HIS is to be inter relating the person's life , saving the different data and recording and maintaining the medical records which results in analyzing the symptoms, investigating the present and past records and providing

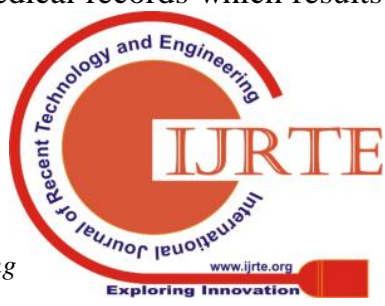


remedies for the diseases in terms of correct medical decisions. The concept of HIS enrich the Hospital statistics structures, in addition to that overall performance of the hospital has enriched which gives a benefit that fee management and commitment on patients. Even though the lots of advantages are related with HIS, the use of HIS and automation of health records is in slow condition.

Healthcare delight has received extra importance, specifically in growing international locations. It is both a utility grade indicator and a perfect component. Steady healthcare systems permit healthcare vendors to deliver better and great facility and price to sufferers. Previous studies indicate that management elements associated with HISs are the links to successes and disasters of these structures in the latest years. For this reason, factors associated with HIS quality have to be considered within the making plans of such systems for implementation and the managers have to also acquire the specified trainings.

HIS structures generally want a lot of complicated related adjustments and aid throughout the process of personalization and final tuning. HIS hardware and software cannot, in reality, be used out of scope. As a substitute, physicians and other healthcare experts need to deliver out much complicated and time eating sports to customize, modify and supplement the HIS product before being in a position to generate benefits from this new technology. HIS need a lot of technical support from the numerous software, hardware, networking, and carrier providers whilst technical problems appear, such as bad consumer software interfaces, gradual computer machines or networks or difficult statistics entry and retrieval especially while the hardware is old. Furthermore, physicians had to redesign their workflow (how they labored in the exam room) and office workflow (who did what obligations; such as records access). As a trendy rule, larger hospitals may want to put into effect complementary changes and request better assist from carriers greater without problems than smaller hospitals due to the fact they have a tendency to have stronger organizational resources together with management know-how, enjoy with beyond technique modifications, economic resources, management, and facts structures guide body of workers

\section{OBJECTIVES}

1. To understand the concept of Hospital information system in the present era.

2. To familiarize the doctors, patients and staff with the new technology of HIS.

3. To educate the public with HIS to access the technology easily.

4. To investigate the influential factors of HIS Operational planning and budgeting, Patient feedback system, Medical Information management, Payment and transaction maintenance, Laboratory management and Clinical imaging information system

5. To explore the impact of Appointments with respective doctors, Manage staff and patient reservations, Perform live conversation with Doctors and Upload and watch the demo videos of patient's profiles on HIS

\section{REVIEW OF LITERATURE}

Earlier, the healthcare companies maintained clinical facts of patients on paper domestically. This custom can be followed only if there exists a proper atmosphere with the prompt management of statistics privacy and security through preserving the paper statistics in a locked cabin. Even the developing use of personal computer systems and current records technology in medical institutions allowed for a mild try to control the privacy and confidentiality of personal medical records. It becomes because of the decentralized and locally controlled infrastructure of every corporation.

The utilization of pc systems in medicinal drug dates again to the Fifties with studies that tried to make bigger the mental capacity of physicians (Stumpf and Freitas, 1997) or handled studies on electrophysiology (Collen, 1986). (Stead, 2007; Stumpf and Freitas, 1997) With the evolution of this device, especially with the capability to concurrently execute diverse obligations starting inside the 1960s, laptop structures began to be used inside the processing of statistics in large hospitals, in each administrative and monetary capabilities for the gathering of statistics and the improvement of research initiatives The use of microcomputers, beginning inside the Seventies, brought the idea of allotted processing, growing the amount of systems in use in massive hospitals.

Various studies have been taken up with regard to HIS, and these researches have paid unique focus on ways to adopt HIS and its services. The results of the studies honestly have improved our access toward the elements that encourage health-care specialists for adopting HIS. But, if usage of HIS is made a must, the technique of ways to boom their usage is an additional critical issue that should be centered upon. Moreover, considering there are numerous variants of HIS, along with each of them having various features and users, it would be considerable to focus on specific HIS and feasible users to higher apprehend those determinants which could enhance HIS use by means of its ultimate customers.

Daiping Hu et.al. (2005) in their paper critiques the HIS that are broadly used in lots of hospitals in countries like China especially to offer a less difficult and quicker manner for day by day clinical duties/sports with a GUI. Also presents for overcoming a few of the shortcomings of HIS, eg. HIS aims at enhancing first-class of fitness care offerings, however, do now not have a way of comparing/measuring the ones.

"Healthcare encompasses exorbitant and complex facilities which created a profound effect on cost and the quality of patient's daily life routine." (Berry,2007). "Various establishments in the healthcare sector are waiting to indulge in electronic healthcare systems because conventional clinical records are limited in pooling the basics of present medicinal drug." (Shortliffe, 2000)

Hospitals are records-intensive businesses and invest great sums on data management and processing, which must be completed using appropriate facts structures. A HIS is a pc-based totally gadget designed to allocate the management of the executive and scientific information inside a medical institution. The most important

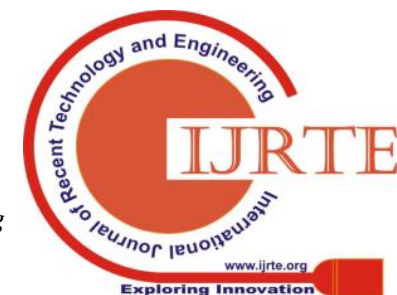


purpose of the device is improvement within the quality of the care provided.

The benefit of HIS has been visually appeared by the way of literature reviews, even though it is hard to use due to the variety of choices, directions and display aids. A main challenge associated with the HIS is to be recording development notes and it is very difficult to display the powerful approaches of HIS. The cost of introduction associated with the HIS is main big problematic scenario of any hospital. If a hospital with minimum patients suffers in terms of attaining advantages and a hospital with maximum patients suffer in terms of attaining and fulfilling the benefits of quality improvements associated with HIS. Though hospitals are introducing HIS practice, dealer evaluation, voice recognition, Tablet computer systems, computers on wheels is a problematic one. Creating consumer friendly software is a challenged one in healthcare industry and healthcare domain. Both the concept called paperless and electronic forces the healthcare experts to change the structures and change the work flow.

"Development of generation will enhance the user proximity and private protections contain using unique technologies. Safety of affected person records may be performed via enforcing security rules to govern access, appropriate authorization earlier than releasing the health information and via offering extra safety features to more touchy information." (Chilton et al., 1999).

Touchy health facts, consisting of HIV popularity, obstetric records, and mental fitness records may want to grow to be greater easily on hand as fitness statistics end up completely automatic. If sensitive fitness records are supplied via approach of others, this will virtually constitute a breach of the affected person's privacy. Healthcare companies and extraordinary stakeholders have a responsibility to keep the confidentiality of records and systems and need to discourage get entry to by means of unauthorized users.

Healthcare delight has won extra importance, particularly in growing countries. It is each a service exceptional indicator and a nice element. Sturdy healthcare structures allow healthcare vendors to supply higher first rate and cost to sufferers. Previous research suggests that manipulate factors related to HISs has been connection with successes and failures of those systems in current years. Therefore factors associated with HIS nice ought to be taken into consideration in planning of such structures for implementation and the managers have to moreover gain the desired trainings.

\section{RESEARCH METHODOLOGY}

To meet the research objectives, doctors of Tamilnadu were selected as a target audience. For the conduct of this study 776 doctors in multi specialty hospitals were selected on a random sampling basis by using Sekaran and Bougie (2010) sample size table. The data was collected by using structured questionnaire and the analysis was made based on the response from the doctors.

\section{ANALYSIS AND INTERPRETATION}

The following diagram shows the relationship between endogenous and exogenous variables. From the diagram it is revealed that, exogenous variables Appointments with respective doctors, Manage staff and patient reservations, Perform live conversation with Doctors and Upload and watch the demo videos of patient's profiles have a significant relationship with endogenous variables Operational planning and budgeting, Patient feedback system, Medical Information management, Payment and transaction maintenance, Laboratory management and Clinical imaging information system.

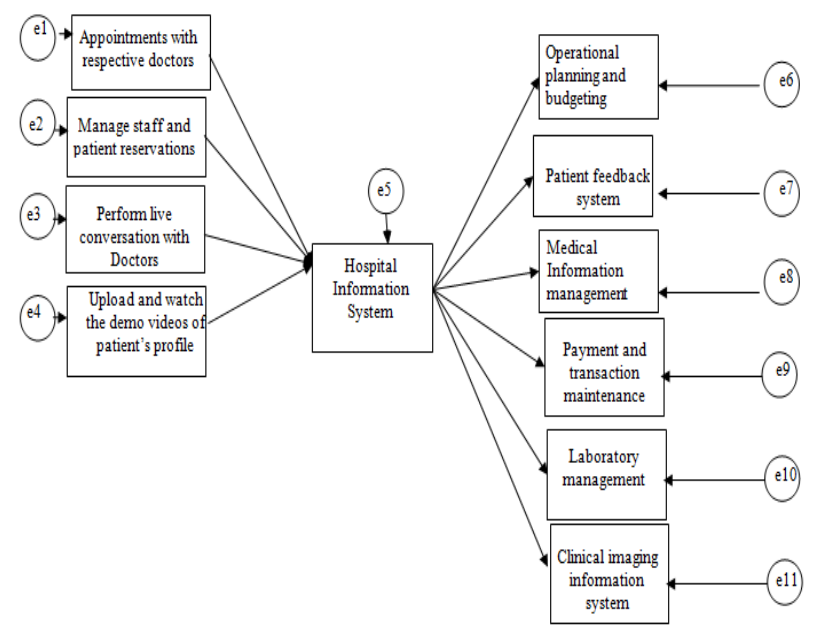

Figure.1.Empirical results of the proposed model

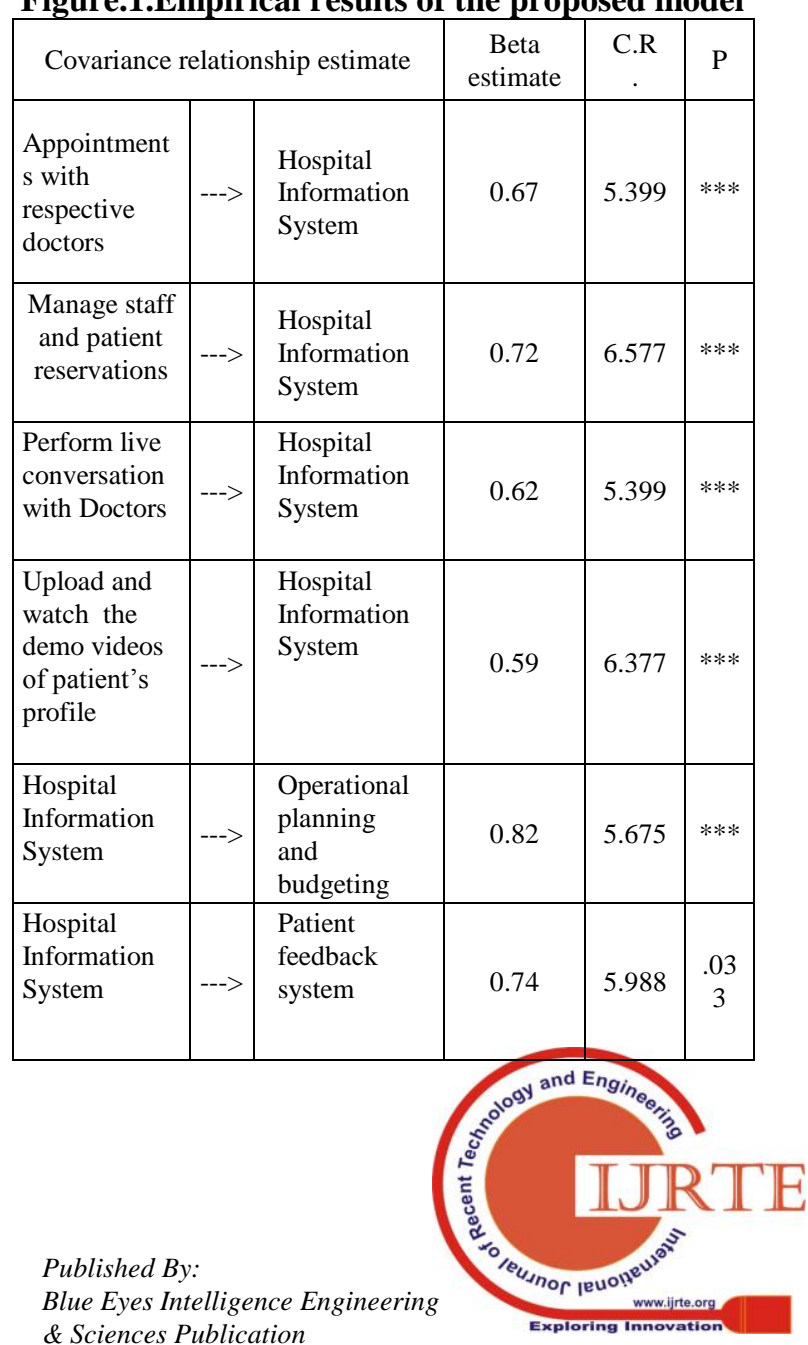




\begin{tabular}{|l|c|l|c|c|c|}
\hline \multicolumn{2}{|c|}{ Covariance relationship estimate } & $\begin{array}{c}\text { Beta } \\
\text { estimate }\end{array}$ & $\begin{array}{c}\text { C.R } \\
\cdot\end{array}$ & $\mathrm{P}$ \\
\hline $\begin{array}{l}\text { Hospital } \\
\text { Information } \\
\text { System }\end{array}$ & $--->$ & $\begin{array}{l}\text { Medical } \\
\text { Information } \\
\text { managemen } \\
\mathrm{t}\end{array}$ & 0.83 & 8.927 & $* * *$ \\
\hline $\begin{array}{l}\text { Hospital } \\
\text { Information } \\
\text { System }\end{array}$ & $--->$ & $\begin{array}{l}\text { Payment } \\
\text { and } \\
\text { transaction } \\
\text { maintenance }\end{array}$ & 0.56 & 6.916 & $\begin{array}{c}.02 \\
1\end{array}$ \\
\hline $\begin{array}{l}\text { Hospital } \\
\text { Information } \\
\text { System }\end{array}$ & $--->$ & $\begin{array}{l}\text { Laboratory } \\
\text { managemen } \\
\mathrm{t}\end{array}$ & 0.81 & 7.625 & .03 \\
\hline $\begin{array}{l}\text { Hospital } \\
\text { Information } \\
\text { System }\end{array}$ & $--->$ & $\begin{array}{l}\text { Clinical } \\
\text { imaging } \\
\text { information } \\
\text { system }\end{array}$ & 0.79 & 5.114 & $* * *$ \\
\hline
\end{tabular}

Table.1. Covariance relationship estimation

Structural diagram of the analysis presented in Figure 1, depicts the standardized model based on the exogenous variables such as Appointments with respective doctors, Manage staff and patient reservations, Perform live conversation with Doctors and Upload and watch the demo videos of patient's profiles shows the relationship between Hospital Information System. Table 1 represents the results of the Covariance relationship estimate among the dependent variable and mediating variable. The critical value, which is more than 1.96, is considered to be significant (David Garson, 2016).

The critical value of Hospital Information System have a significant relationship with the endogenous variables such as Operational planning and budgeting (5.675), Patient feedback system (5.988), Medical Information management (8.927), Payment and transaction maintenance (6.916), Laboratory management (7.625) and Clinical imaging information system (5.114)

\section{CONCLUSION AND RECOMMENDATIONS}

Popularity, pleasure, and normal fulfillment are the results of enhanced functions and performance of the machines. HIS upgrades, the program speed of a software, sensitivity and enriched availability of computer systems and laptops. Screen designs of the HIS needs to be present with good replication of the functions, performance and options along with that it should be more user friendly with a component of adjustments. The traditional methods of medical recording are a time consuming process which insist the person to use keyboards, labor oriented in addition it is time consuming. Instead of this old recording process, HIS is in present trend with new innovative technologies which include dictation structures and automatic voice recognition

The second recommendations insist that proper user manuals and training aids will be useful for the HIS users; which results in error free work process along with the proper saving time for the users in terms working hours and improved performance. For the successful implementation of the HIS process more technical support is needed from the vendors.

\section{REFERENCES}

[1] Collen, M. F. (1986). Origins of Medical Informatics. In Medical informatics [Special Issue].The Western Journal of Medicine. Computer Science, 2015.

[2] Degoulet P, Fieschi M. Introduction to Clinical Informatics. Health Informatics Series. New York, NY: Springer-Verlag; 1997.

[3] Hoffmann, M., Loser, K.U., Walter, T., \& Herrmann, T. (1999, November). A design process for embedding knowledge management in everyday work. In Proceedings of the international ACM SIGGROUP conference on supporting group work (pp. 296-305). ACM.

[4] Khalifa, Mohamed, and Osama Alswailem. "Hospital Information Systems (HIS) Acceptance and Satisfaction: A Case Study of a Tertiary Care Hospital", Procedia

[5] Kimiafar K, Sarbaz M, Sheikhtaheri A, Azizi A. The impact of management factors on the success and failure of health information systems. Indian Journal of Science and Technology. 2015; 8(27):1-9

[5] Kuang-Ming Kuo, Chung-Feng Liu, Paul C. Talley, Su- Ya Pan "Strategic Improvement for Quality and Satisfaction of Hospital Information Systems", Journal of Healthcare Engineering, 2018

[6] McDonald, C. J. (1997). The barriers to electronic medical record systems and how to overcome them. Journal of the American Medical Informatics Association, 4(3), 213-221.

[7] P. W. Handayani, A. N. Hidayanto, A. A. Pinem, I. C. Hapsari, P. I. Sandhyaduhita, and I. Budi, "Acceptance model of a hospital information system," International Journal of Medical Informatics, vol. 99, pp. 11-28, 2017.

[8] R.H. Miller, I. SimPhysicians' use of electronic medical records: barriers and solutions Health affairs, 23 (2) (2004), pp. 116-126

[9] Radhika V, Assaf RR, Al-Assaf AF. JHQ 197- Making patient safety and quality improvement act of 2005 work. Journal for Healthcare Quality. 2007; 29(4):6-10.

[10] Stead, W.W. (2007, February). Rethinking Electronic Health Records to Better Achieve Quality and Safety Goals.Annual Review of Medicine.

[11]Stumpf, M. K. \& Freitas, H.M.R. (1997). de. A gestão da informação em um hospital universitário: o processo de definição do Patient Core Record. Rev. adm. Contemp. 